\title{
A Web Based Google Earth Engine Approach for Irrigation Scheduling in Uttar Pradesh India Using Crop Water Stress Index
}

\author{
Pragati Singh*, Ashutosh Singh, Rajesh Kumar Upadhyay \\ Agriculture Resources Division, Remote Sensing Applications Centre, Lucknow, Uttar Pradesh, India \\ Email address: \\ singh22pragati@gmail.com (P. Singh),nirashu@gmail.com (A. Singh), rsacupard@gmail.com (R. K. Upadhyay) \\ ${ }^{*}$ Corresponding author
}

\section{To cite this article:}

Pragati Singh, Ashutosh Singh, Rajesh Kumar Upadhyay. A Web Based Google Earth Engine Approach for Irrigation Scheduling in Uttar Pradesh India Using Crop Water Stress Index. American Journal of Remote Sensing. Vol. 9, No. 1, 2021, pp. $42-46$.

doi: 10.11648/j.ajrs.20210901.15

Received: March 10, 2021; Accepted: March 25, 2021; Published: April 1, 2021

\begin{abstract}
Upgrading water use in agricultural crops requires advancements in location of crop water stress for irrigation scheduling, at different phases of the developing season to limit crop physiological harm and yield reduction. Potential of satellite data provide spatial and temporal dynamics of crop growth condition under water stress and analyse for suggestion of irrigation. This study is based on real time open-source web-based Google Earth Engine (GEE) approach for irrigation scheduling at field level based on its water stress condition. Sentinel-2 data was used for detecting water stress using the NDVI and NDWI indices. NDVI shows the crop growth and health whereas NDWI its water stress condition, by combining both the indices we have generated a new index, which is Crop Water Stress Index (CWSI) to schedule the irrigation. The real time Sentinel-2 data was used extract NDVI and NDWI indices and by combining both the indices a new indice was generated for detecting crop water stress condition to schedule the irrigation in real time. The output comes in five group of water stress condition as; No Stress, Low stress, Moderate stress, High stress and Severe stress. Using the result of CWSI the immediate irrigation should be given to those fields which are facing severe and high stress, delayed in moderate and low stress and no irrigation in no-stress. The overall study indicates that, GEE provide a real time better platform for analysing Crop Water Stress situation for scheduling proper irrigation practices for proper growth of crops to improve the production and income of farmers as well as It helps the irrigation planner for proper management of canals and other irrigation resources to the wastage of water.
\end{abstract}

Keywords: CWSI, Irrigation Scheduling, NDVI, NDWI

\section{Introduction}

Detection of water stress can help farmers in taking proper measure for reducing negative impacts on irrigation management. Satellite based monitoring of Crop Water Stress is very important for precision agriculture, which realise on time of irrigation to ensure crops will not suffer from water stress and produce maximum potential yield under limited water condition. [1-6] Potential of satellite data provide spatial and temporal dynamics of crop growth condition under water stress and analyze for suggestion of irrigation.

Remote sensing and GIS data can provide a better platform to detect crop water stress to suggest irrigation scheduling. This research was based on the open source Google Earth
Engine Platform to assess the Water Stress during the growing season of crops in Uttar Pradesh. So that better timing can be found out to suggest irrigation scheduling.

\section{Study Area \& Data Sets Used}

The study area was taken as whole Uttar Pradesh state of India (Figure 1). With the total area of 2,187, $28.25 \mathrm{~km}^{2}$, and Situated between $23^{\circ} 52^{\prime} \mathrm{N}$ and $31^{\circ} 28^{\prime} \mathrm{N}$ latitudes and $77^{\circ} 3^{\prime}$ and $84^{\circ} 39^{\prime} \mathrm{E}$ longitudes, is the fourth largest state of India. It plays a significant role in the contribution of national food grain stock. Agriculture is the major industry of the state and is source of livelihood for 72 percent of its population. Uttar Its economy is basically based on the agricultural productions 
[1] Uttar Pradesh has good networks of canal for irrigation, but due to lack of proper knowledge regarding irrigation timing, a huge amount of water wasted and land degradation was occurred which results reduction in yield.

To overcome with this problem a proper irrigation management is required. The real-time Sentinel-2 data provided on GEE with $10 \mathrm{~m}$ spatial and 5 days temporal resolution was used to generate Crop Water Stress map of Uttar Pradesh for irrigation management and scheduling. [2]

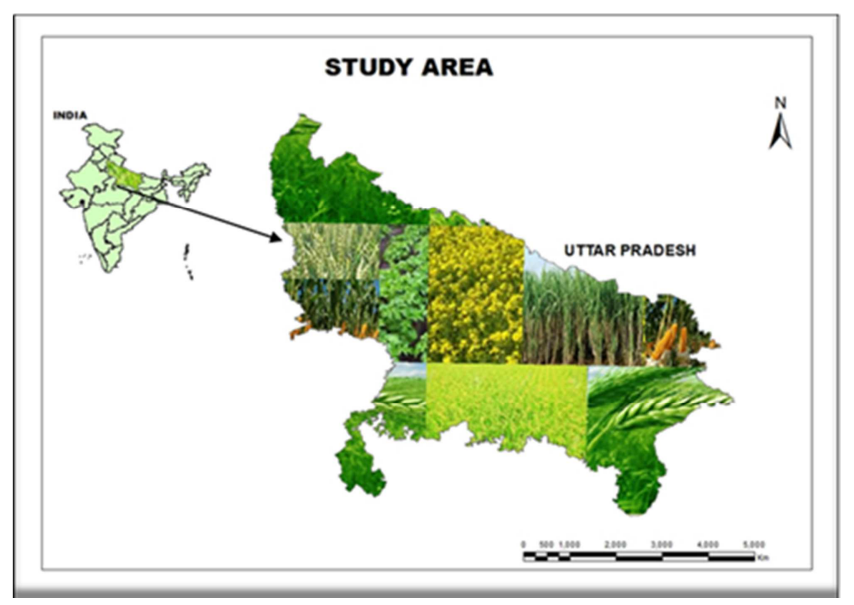

Figure 1. Study area. [3]

\section{Methodology}

The research work conducted in Uttar Pradesh state of India by combining NDVI and NDWI. [4] The methodology adopted in this research work has been given in figure 2 and described in following 3.1 to 3.4 subheads.

\subsection{NDWI Estimation}

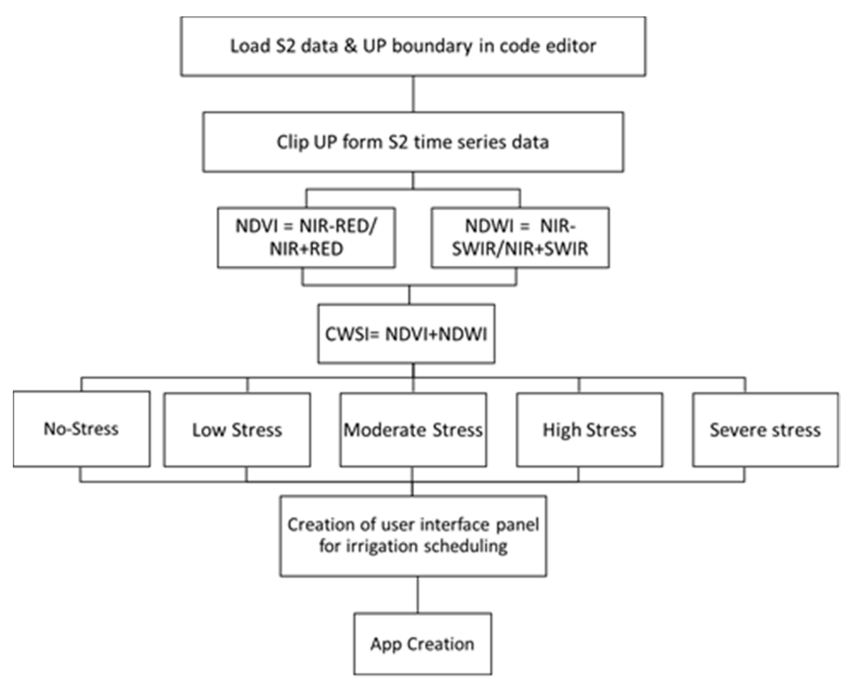

Figure 2. Methodology flow chart.

Normalized Difference Water Index (NDWI) is an indicator of the water stress condition in the leaf of crops canopy. Higher the NDWI values higher the water stress in the plant and lower the NDWI value lower the water stress.
So to examine the water stress condition in the crop NDWI has been calculated for the study area. [5]

Sentinel-2 bands 11 and 8 as; shortwave infra-red (SWIR) and near-infra red (NIR) bands were used to generate NDWI with the following formula:

$$
\begin{gathered}
\mathrm{NDWI}=(\text { Band } 8(\mathrm{NIR})-\text { Band } 11(\mathrm{SWIR})) /(\text { Band } 8(\mathrm{NIR}) \\
+ \text { Band } 11(\mathrm{SWIR}))
\end{gathered}
$$

\subsection{NDVI Estimation}

Normalized Difference Vegetation Index (NDVI) is an indicator of the crop growth and its health. The NIR band is sensitive for crop chlorophyll content. [6] As the crop growths its chlorophyll content also increases and the reflectance in NIR is increases and decreases in Red band. By calculating NDVI we have analyse the crop growth and its health. [7] Higher the NDVI healthier the crop and lower the NDVI vice-versa. [8]

Sentinel-2 bands 8 and 4 as; shortwave infra-red (NIR) and near-infra red (RED) bands were used to generate NDVI with the following formula:

$$
\begin{gathered}
\mathrm{NDVI}=(\text { Band } 8(\mathrm{NIR})-\text { Band } 4(\mathrm{R})) /(\text { Band } 8(\mathrm{NIR})+ \\
\text { Band } 4(\mathrm{R}))
\end{gathered}
$$

\subsection{CWSI Estimation}

Crop Water Stress Index is an index which was used to find the crop water stress condition. [9] It is the combination of NDVI and NDWI. As it's known that NDVI is used to know the health and growth of crop whereas the NDWI is for water stress. [10] By combining both of Indices CWSI was generated to find Crop Water Stress in crop for proper irrigation scheduling in the study area. $[8,15,16]$

The CWSI was extracted using NDVI and NDWI values following that formula;

\section{$\mathrm{CWSI}=\mathrm{NDVI}+\mathrm{NDWI}$}

The output generated by using it has been grouped in five categories on the basis of its health and water stress condition, which is described in the following points; $[17,18]$

CWSI $>1$ - group 1 and class 1 -which represents the normal condition, where No water stress with dense vegetation and low temperature and sufficient water

Group 2 and class 2 when CWSI $>0.8 \&<1$ - represents low water stress condition and slightly low surface temperature with sparse vegetation and moderate water content

Group 3 and class 3 when CWSI $<0.8 \&>0.5-$ which represents the moderate water stress condition due to sparser vegetation and low water stress

Group 4 and class 4 when CWSI $<0.5 \&>0.35-$ which represents, high stress condition, when crop is under high water stress due to higher surface temperature and very low water content with sparse vegetation

Group 5 and class 5 when CWSI $<0.35$ - which represents, severe stress condition, when crop is under high water stress due to higher surface temperature and very low water content with very low density of vegetation. 


\subsection{Cropped Area Extraction}

Since study was focused crop water stress condition, using NDVI data the study has been done only on the cropped area using the NDVI values of crop. As well as the nonagricultural area has been masked out using the LULC mask and study has been conducted only on those areas where NDVI is greater than 0.25 [19].

\section{Results \& Discussions}

This study is an attempt to evaluate the performance of water stress condition of crops to suggest irrigation in the study area. The output was generated in five groups or classes. Which has been defined as; group 1-No water stress, group 2-low water stress, group 3-moderate water stress, group 4-high stress condition and group 5-severe stress condition.

It was also observed by this research work that; The Normalized Difference Vegetation Index (NDVI) and the Normalized Difference Water Index (NDWI), these two vegetation indices were integrated for evaluating the vegetation growth, health and water status condition, to analyse the Crop Water Stress Index (CWSI) in the study area for proper irrigation scheduling and management.

The Google Earth Engine (GEE) code editor platform has been used for real time analysis for CWSI in the study area. Using the GEE code editor platform user friendly CWSI app has been created for proper time selection for irrigation scheduling. Figures 3, 4 and 5 shows; how the CWSI app works.

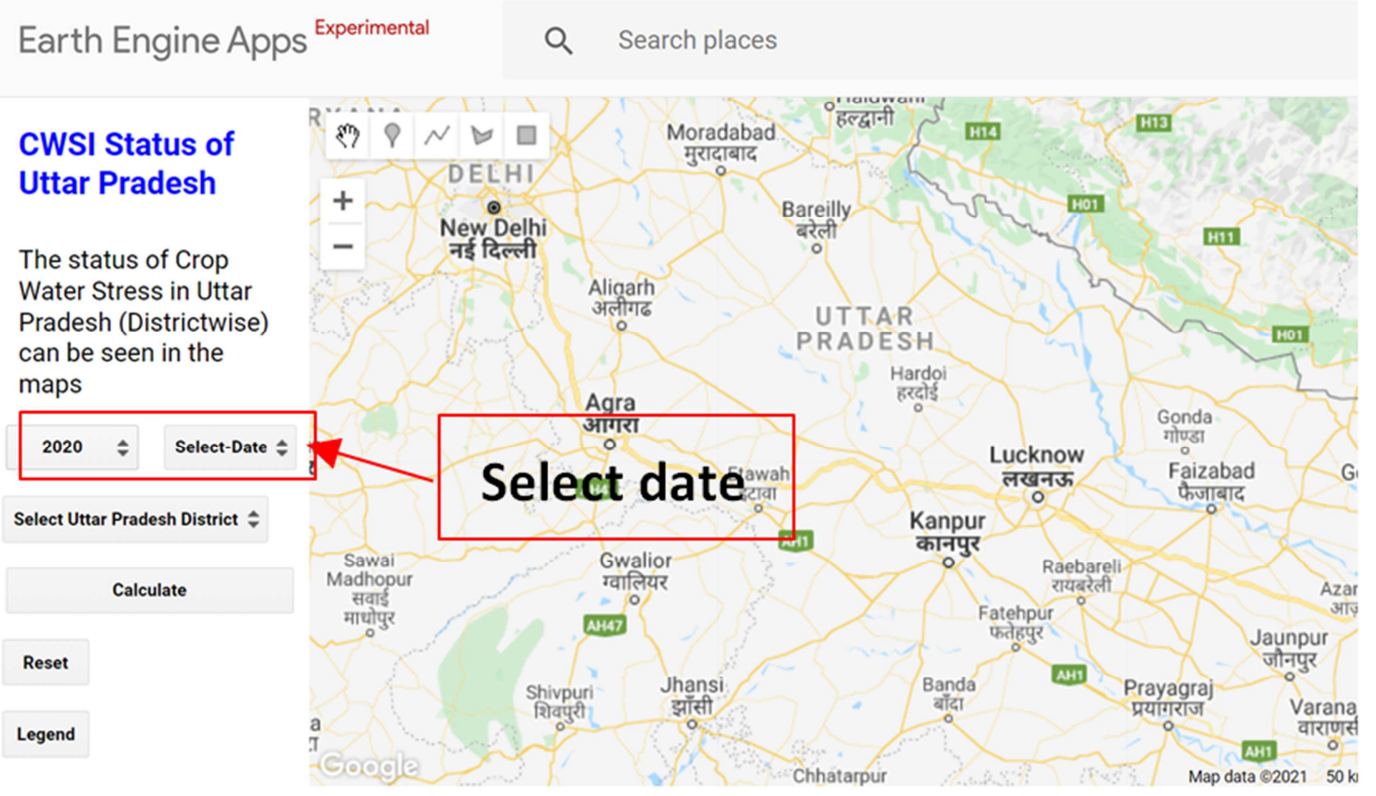

Figure 3. CWSI date selection panel for real time crop water stress monitoring.

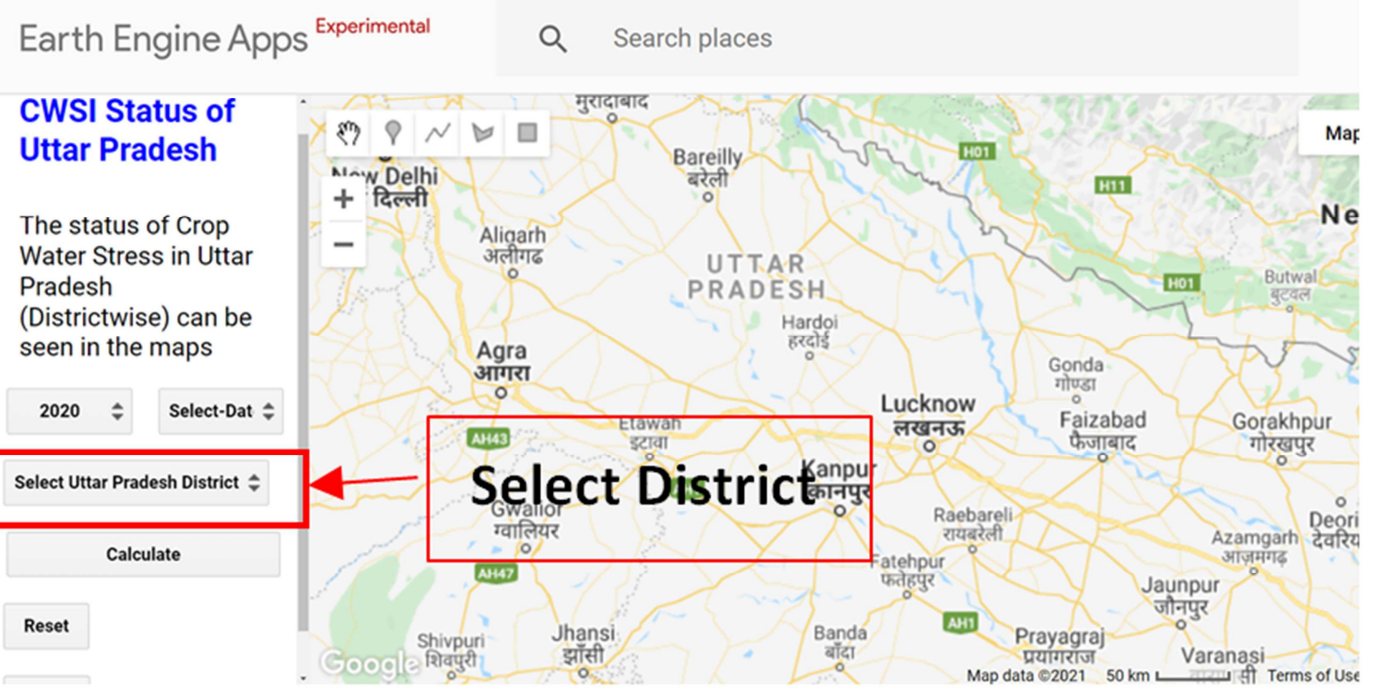

Figure 4. CWSI district selection panel for real time monitoring. 


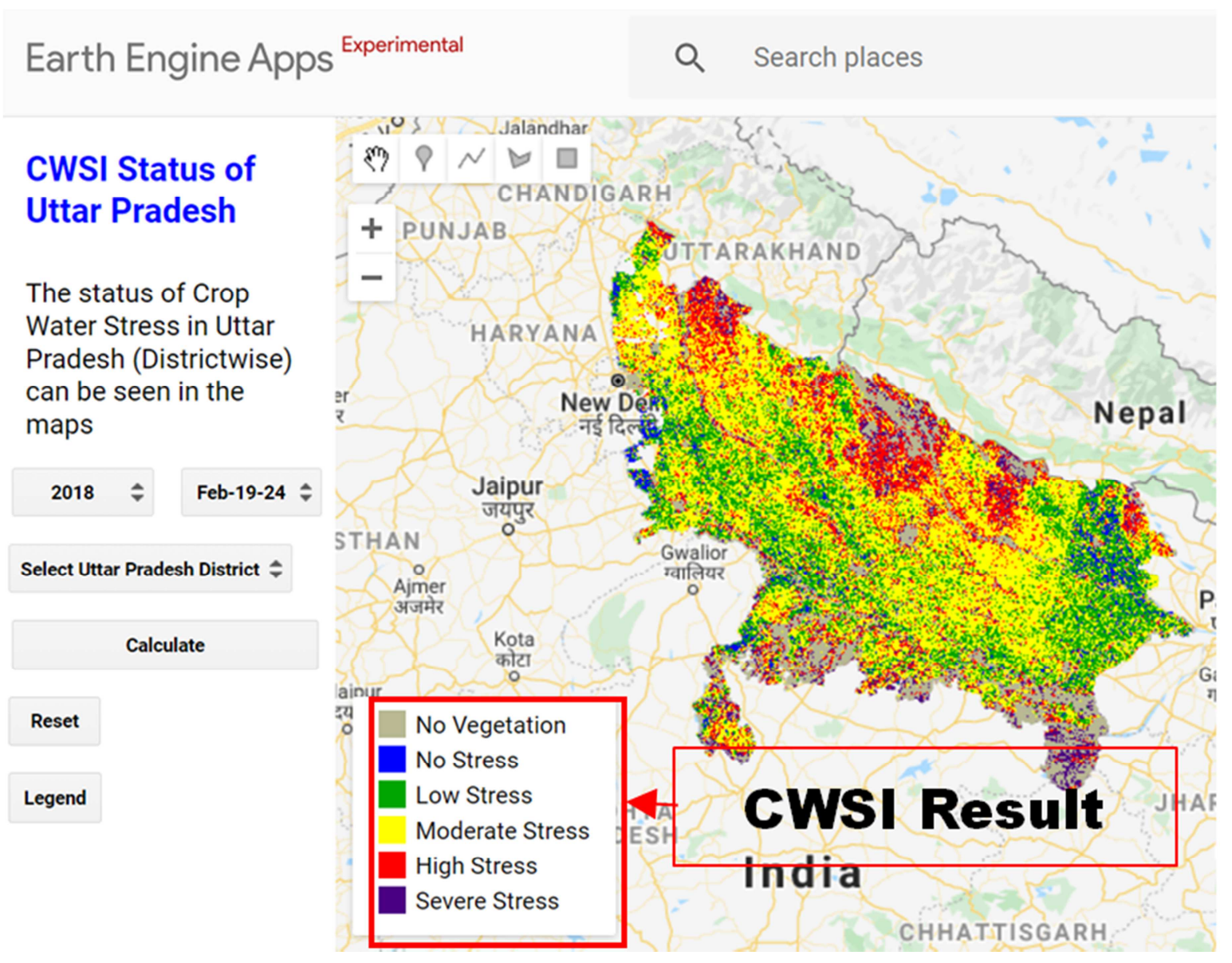

Figure 5. Real time CWSI result for irrigation Management.

By the above figures 3, 4 and 5 we can understand the working process of CWSI app. Figure 3 shows, when we open the app there is an Crop water stress panel is opened, when we click on it there is another panel on the left side of app is opened which is for date selection (figure 4), where you can enter start date and end date, it is notable that Sentinel-2 data is available at 5 days interval. So you have to give start date just before five days back of your end date to get full image of Uttar Pradesh for CWSI to schedule the irrigation on the basis of it stress as; No water stress- No irrigation, Low water stress- irrigation can be delayed, Moderate water stress- irrigation is required but can be delayed for few days, High stress condition- irrigation is required and can't be delayed otherwise plant will dried and produce low yield, and Severe stress condition- - immediate irrigation is required and can't be delayed because plant is in dry condition and losing their yield capacity (figure 5).

\section{Conclusion}

Through this research work it was concluded that; there is a negative correlation between CWSI and crop yield. CWSI is an easy and reliable method for proper irrigation scheduling. The overall study results that the irrigation management to the crop in study area can be done through this method and GEE provides a very good platform to operationalize this research work.

By this research work the best timing for irrigation scheduling has been results as; when crop has under severe or high water stress condition as well as if we provide irrigation during moderate water stress condition the production per hectare will be increases. This research work will be helpful to the farmers as well as the planner for planning proper irrigation scheduling.

\section{References}

[1] "AGRICULTURE, COOPERATION \& FARMERS WELFARE," Government of India, 2016. [Online]. Available: https://agricoop.nic.in/sites/default/files/DroughtManual.pdf. [Accessed 105 2018].

[2] A. A. \&. N. D. C. Alderfasi, "Use of crop water stress index for monitoring water status and scheduling irrigation in wheat," Agricultural Water Management, pp. 69-75, (2001)..

[3] "Chapter 1 The role of water in agricultural development," FAO, 2003.2 [Online]. Available: http://www.fao.org/3/y5582e/y5582e04.htm. [Accessed 1802 2018].

[4] D. R. EM Perry, "Sensitivity of Narrow-Band and Broad-Band Indices for Assessing Nitrogen Availability and Water Stress in an Annual Crop," Agronomy journal, vol. 100, no. 4, pp. 1211-1219, 2008 
[5] M. A. El-Shirbeny, "Sentinel-1 Radar Data Assessment to Estimate Crop Water Stress," World Journal of Engineering and Technology, vol. 5, no. 2, p. 47, 2017.

[6] "Wikepedia," $2014 . \quad$ [Online]. Available: https://en.wikipedia.org/wiki/Wheat\#: :text=The\%20archaeol ogical $\% 20$ record\%20suggests\%20that,220.4\%20million $\% 20 \mathrm{~h}$ ectares\%2C\%202014).. [Accessed 1604 2018].

[7] P. K. P. S. N. K. R. K. U. a. S. P. S. J. Yadav, "Impact of Canal Restructuring on Agricultural Land Use in 23 Down Haidergarh Canal Command System, Uttar Pradesh, India," International Archives of the Photogrammetry, Remote Sensing and Spatial Information Sciences, Vols. Volume XLII3/W6, no. 345-350, 2019.

[8] C. M. SO Ihuoma, "Recent advances in crop water stress detection," Computers and Electronics in Agriculture, vol. 141, pp. 267-275, 2017.

[9] R. U. H. P. B. M. O. S. V. Pragati Singh, "CROP SUITABILITY ANALYSIS FOR CEREAL CROPS OF UTTAR PRADESH, INDIA," International Archives of the Photogrammetry, Remote Sensing \& Spatial Information Sciences, vol. XLII, no. 5, pp. 353-360, 2018.

[10] "Use of crop water stress index for monitoring water status and scheduling irrigation in wheat," Agricultural Water Management.

[11] M. O. JH Patel, "Deriving crop calendar using NDVI timeseries," The International Archives of Photogrammetry, Remote Sensing and Spatial Information Sciences, vol. 40, no. 8, pp. 869-873, 2014.
[12] S. S. D. G. S. S. R. K. Behl, "Indices of Drought Tolerance in Wheat Genotypes at Early Stages of Plant Growth," Journal of agronomy and crop, vol. 190, no. 1, pp. 6-12, 2014.

[13] G. R. F. V. A. M. JA Alvarez, Drought Management and Planning for Water Resources, CRC Press, 2005.

[14] S. I. R. R. RD Jackson, "Canopy temperature as a crop water stress indicator," Water resources, vol. 17, no. 4, pp. 1133$1138,1981$.

[15] N. P. M. K. S. S. N Dangwal, "Monitoring of water stress in wheat using multispectral indices derived from Landsat-TM," Geocarto International, vol. Volume 31, no. 6, pp. 682-693., 2016.

[16] P. S. S. P. S. J. N. K. a. R. K. U. Sunil Kumar Yadav, "SOIL MOISTURE ANALYSIS OF LALITPUR DISTRICT UTTAR PRADESH INDIA USING LANDSAT AND SENTINEL DATA.," International Archives of the Photogrammetry, Remote Sensing \& Spatial Information Sciences, Vols. Volume XLII-3/W6, pp. 351-356, 2019.

[17] Ulaval.ca, "Thermal water stress index from satellite images," [Online]. Available: http://theses.ulaval.ca/archimede/fichiers/21726/ch06.html. [Accessed 1204 2018].

[18] A. V. F. A. JD Jang, "Thermal-water stress index from satellite images," International Journal of Remote Sensing, vol. 27, no. 8, pp. 1619-1639, 2006.

[19] H. C. B. D. D. U. S. L. \&. K. S. C. Stimson, "Spectral sensing of foliar water conditions in two co-occurring conifer species: Pinus edulis and Juniperus monosperma," Remote Sensing of Environment, vol. 96, no. 1, pp. 108-118, 2005. 